\title{
Radio-Induced Chondrosarcoma of the Scapula: A Rare Localization (About One Case)
}

\author{
Daoudi M*, Azriouil 0, Rifki F, Mortaji A, Nadir Y, Margad 0 and \\ Koulali KI \\ Department of Traumatology - Orthopedics, Avicenna Military Hospital, Morocco
}

*Corresponding author: Daoudi Mohamed, Department of Traumatology -

\section{Case Report}

Volume 3 Issue 1

Received Date: March 16, 2019

Published Date: April 09, 2019

Orthopedics, Avicenna Military Hospital. Marrakech. Morocco, Tel: 0661476426; Email: daoudimonsa@gmail.com

\section{Abstract}

Radiation-induced second malignancies, particularly radiation-induced sarcomas, are rare. We report the case of a 62year-old Moroccan man diagnosed as having chondrosarcoma of his right scapula, who was irradiated 10 years ago for stage IIIB non-small cell lung cancer. This case was managed by a Total scapulectomy with the suspension with good functional and oncological outcomes.

Keywords: Radio induced chondrosarchoma; Total scapulectomy

\section{Introduction}

The chondrosarcoma of the scapula can have a primary or secondary origin, either by degeneration of a benign tumor of cartilaginous origin, or by irradiation which is rare with a frequency of $0,5-2 \%$. The authors report a rare case of a radio-induced chondrosarcoma of the scapula treated by total scapulectomy, with review of the literature.

\section{Case Presentation}

A 62-year-old Moroccan man, retired from the army, married, a chronic tobacco smoker, without any medical history, underwent concomitant chemo radiation for stage IIIB SCC of his right lung in 2007 [1]. His regular follow-up evaluations did not reveal any notable pathologic findings, and he did not need to take any specific medication. However, 10 years later he presented a right scapula pain. He stopped smoking tobacco in 2007, and suffered from right scapula pain for 3 months. A clinical examination found a fixed, sensitive right scapular mass that measured $10 \mathrm{~cm}$ at its big axis (Figure 1). Motricity of arms and inferior members was well conserved without any involuntary movements. Muscular force was preserved as well as sensitivity (light touch, temperature, vibration, joint position sense) .A Magnetic resonance imaging (MRI) of the scapular region showed malignant tumor process centered on the supraspinatus and infraspinous muscles with hypo signal at T1 and heterogeneous hyper signal at T2 measuring $90 \mathrm{~mm}$ on the longest axis and $60 \mathrm{~mm}$ on the shortest axis (Figure 2). Laboratory tests did not reveal any abnormalities, showing good liver and renal functions. A surgical biopsy of the tumor was performed. Histopathological examination showed a grade 1 chondrosarcoma. An extension assessment, including CT of his chest and abdominal ultrasonography, did not find distant metastasis surgical resection was performed with safe margins (Figure 3). The surgical procedure consisted of a resection of his right scapula, with fixation of his right arm (Figure 4). A follow-up at 12 months (clinical examination and CT scan) did not show any sign of recurrence or specific complication. 


\section{International Journal of Surgery \& Surgical Techniques}

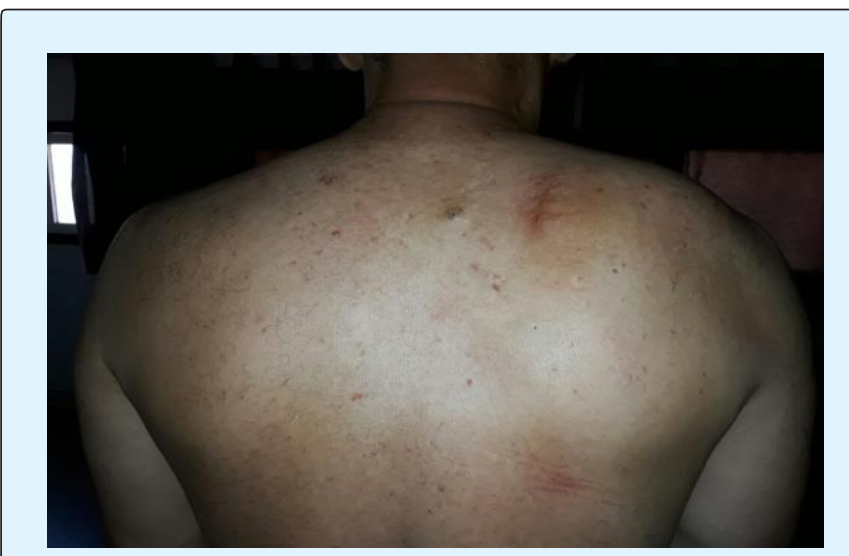

Figure 1: Right scapular mass.

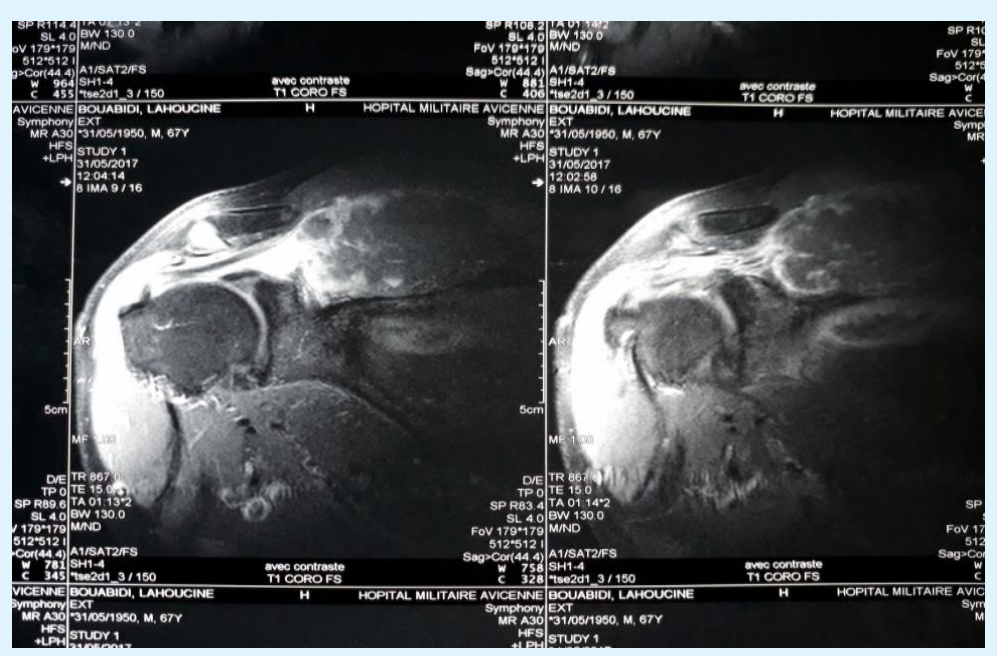

Figure 2: Magnetic resonance imaging (MRI) of the scapular region showed malignant tumor process.

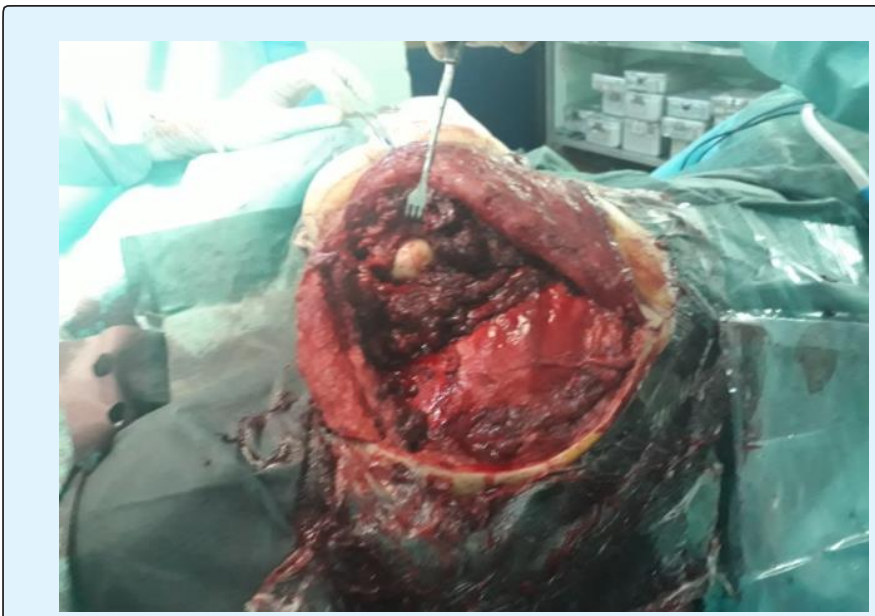

Figure3: Scapulectomy with safe margins. 


\section{International Journal of Surgery \& Surgical Techniques}

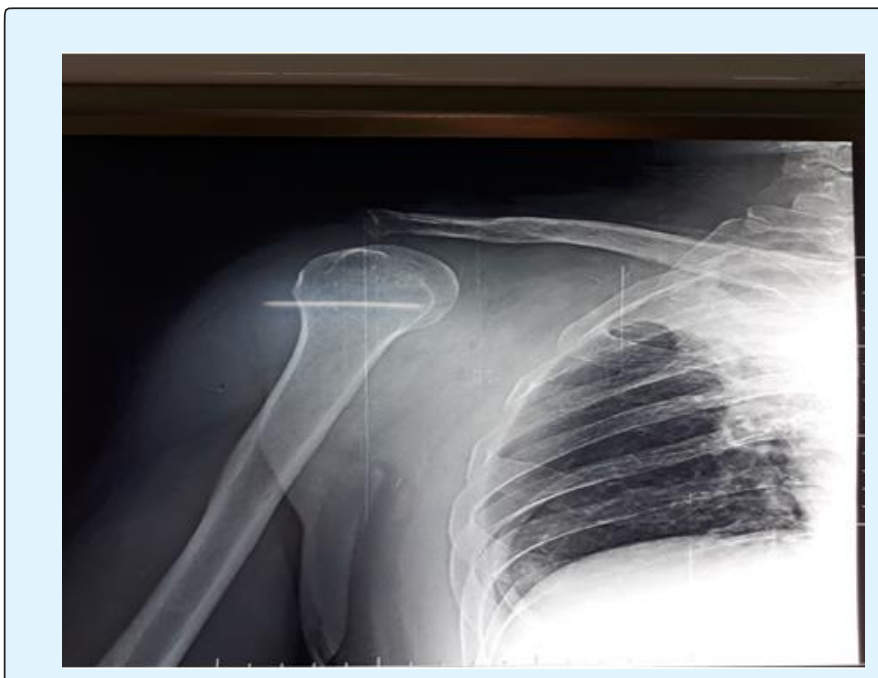

Figure4: X-ray of the right shoulder in postoperative.

\section{Discussion}

Radiation-associated sarcoma (RAS) is a rare, malignant tumor of mesenchyme tissue that arises in the setting of radiation exposure, most commonly from radiation therapy (RT) for the treatment of another primary oncologic process [2].

The diagnostic criteria for RAS were first proposed in 1948 by Cahan in a case series of 11 sarcomas that manifested in irradiated bone. This definition of radiation-associated sarcoma was later revised in 1971 by Arlen et al. and in 1999 by Murray, et al. [3].

\section{Criteria for RAS include the following:}

1) The sarcoma must have arisen in the setting of previous radiation exposure within the $5 \%$ isotope line of the irradiated field (i.e. the volume of tissue receiving at least $5 \%$ of the prescription dose),

2) The histologic features of the sarcoma must be of a different pathology than that of the primary malignancy, and

3) There must have been no evidence that the sarcoma was likely to have been present prior to the onset of radiation [4].

The required length for latency period following initial treatment is controversial, as recent literature has suggested that as few as 6 months of latency can suffice for the diagnosis of radiation-associated sarcoma while other authors have suggested a 5-year latency period [5].
The main treatment is the surgical resection of the tumor with a subtotal or total scapulectomy, depending on the size of the tumor [1]. The radiotherapy and chemotherapy do not provide better survival Rates than surgery as a single treatment [6]. For this reason, the surgical planning becomes greatly important and adequate safety margins are needed, which can hinder in some cases the function of the affected limb. The use of surgery that pre- serves the basic function of the upper limb and the non-affected articulations, such as the hand and the elbow, become as important as those approaches that try to preserve part of the shoulder articulation, always with an adequate oncological resection. Surgeons may consider the suspension of the limb without reconstruction, but nowadays there are tumor prostheses for the proximal third of the humerus, prosthesis of the scapula or plastic reconstructions with bank grafts for the articular part [7-10].

\section{Conclusion}

The radio induced chondrosarcoma of the scapula remains exceptional. Total scapulectomy with the suspension of the limb showed good functional and emotional results, as well as a good survival rate.

\section{References}

1. Antoni D, Mornex F (2016) Chemo radiotherapy of locally advanced nonsmall celllung cancer: state of the art and perspectives. Curr Opin Oncol 28: 104109. 


\section{International Journal of Surgery \& Surgical Techniques}

2. Burdett SS, Stewart LA, Rydzewska L (2007) Chemotherapy and surgery versus surgery alone in non-small cell lung cancer. Cochrane Database Syst Rev 18(3): CD006157.

3. Siegel R, DeSantis C, Virgo K, Stein K, Mariotto A, et al. (2012) Cancer treatment and survivorship statistics,2012. CA Cancer J Clin 62(4): 220-241.

4. Huvos AG, Woodard HQ, Cahan WG, Higinbotham NL, Stewart FW, et al. (1985) Postradiation osteogenic sarcoma of bone and soft tissues. A clinicopathologic study of 66 patients. Cancer 55(6): 1244-1255.

5. Berrington de Gonzalez A, Gilbert E, Curtis R, Inskip P, Kleinerman R, et al. (2013) Second solid cancers after radiation therapy: a systematic review of the epidemiologic studies of the radiation dose- response relationship. Int J Radiat Oncol Biol Phys 86(2): 224233.

6. Pant R, Yasko AW, Lewis VO, Raymond K, Lin PP (2005) Chondrosarcoma of the scapula: long-term oncologic outcome. Cancer 104(1): 149-158.
7. Mayil VN, Mohanlal P, Bose JC, Gangadharan R, Karthisundar V (2007) The functional and oncological results after scapulectomy for scapular tumours: 216-year results. Int Orthop 31(6): 831-836.

8. Mavrogenis AF, Mastorakos DP, Triantafyllopoulos G, Sakellariou VI, Galanis EC, et al. (2009) Total scapulectomy and constrained reverse total shoulder reconstruction for a Ewing's sarcoma. J Surg Oncol 100(7): 611-615.

9. Chauveinc L, Lefevre S, Malfoy B, Dutrillaux B (2002) Actualités sur les tumeurs radio-induites les études génétiques. Bull Cancer 89(2): 181-196.

10. Altay M, Bayrakci K, Yildiz Y, Erekul S, Saglik Y (2007) Secondary chondrosarcoma in cartilage bone tumors: report of 32 patients. J Orthop Sci 12(5): 415-423. 